\title{
Synergism of Dance Theory and Practice: The Requisite for Dance Development in Nigeria
}

\author{
Christian Ikechukwu Nwaru \\ University of Northampton, Northampton, UK \\ Email: chrisnwaru@yahoo.com
}

Received 22 September 2014; revised 25 October 2014; accepted 9 November 2014

Copyright (C) 2014 by author and Scientific Research Publishing Inc.

This work is licensed under the Creative Commons Attribution International License (CC BY). http://creativecommons.org/licenses/by/4.0/

\begin{abstract}
In the history of dance development, organise systems of accepted knowledge as applied in variety of circumstances were used in explaining different set of phenomena that informed the action, operation or behaviour of dance and vis-à-vis. This paper traces the long aged dichotomy between the theorists and pragmatic dance practitioners in Nigeria. The researcher observes that this unhealthy division among the dance artists in Nigeria is delaying the progress of the already marginalised section of the performative art. He submits that for virile development of dance to take place in Nigeria, the balance application of the theory and practice of dance art is necessary.
\end{abstract}

\section{Keywords}

\section{Synergism, Theory and Practice, Requisite, Dance Development, Nigeria}

\section{Introduction}

In Nigerian like other African societies, a dancer does not need to attend a formal school to know how to dance especially the traditional dance form. Dance training and practice take place within the communities, at the market squares or the village halls. In some occasion, the door is open for people to participate. As a result of this commonness in dance and dance training, some people have no regard for dancers, others are with the notion that everybody can dance. The researcher has argued somewhere that in Africa, dance has closely been associated with humans in their day-to-day activities, yet the performers of dance are treated with disdain on account of the often non-professional status of the form (Nwaru, 2008). Nwankwo (1977), in his book Danda, observed that in Igbo society, the character Danda who normally participated in his pastimes of oja (flute) blowing and being the life of the party was cajoled as an "efulefu" (useless and worthless person). Thus dance is con- 
ceived from a perspective that disregards the energy, effort and expertise needed in the execution of even the simplest movement. It is a perspective shared by the Yoruba of Western Nigeria, according to Ebun Clark:

The actor (dancer) or any person connected with the theatre was regarded as an "Alarinjo", a name which

Prof. J.A. Adedeji says originated as an abuse and which more or less picks them out and labels them as

"rogues, vagabonds and sturdy beggars" (Clark, 1979: p. 4).

This lack of respect and regard for dancers as observed by Nwankwo and Clack in the 70s is still persistent till date. This has tended to make people look down on dance and dancers, a similar condition to the one that theatre and performing arts graduates suffered for a long before the advent and global explosion of Nigerian Home videos or Nollywood. As a result most dancers prefer to be identified with scholars and academics rather than the pragmatic dancers. In the formal school system in Nigeria, some theatre arts students (mostly dancers) and even lecturers are cajoled because of their involvement in the practice of theatre. This attitude which started a long time ago still exists till today. During the formative years of the Theatre Arts Department in University of Ibadan, Demas Nwoko observes that:

The students loathed practical work because fellow-students from other departments taunted them, branding them as non-academic. So, to prove that their course were academic, they preferred to show off with books by spending their time in the libraries (Nwoko, 1981: p. 464).

This psychological problem was not the affliction of the students alone, as it also affected members of the staff. Demas continues:

They (lecturers) too discovered that they could not progress in a university without showing that they were academics, so practically all of them abandoned the search for an African Theatre and settled down to establishing themselves as reputable academics (Nwoko, 1981: p. 464).

By this mutual shift of emphasis, most of the theatre scholars in Nigerian universities became purely academics, having little or nothing to do with practical's especially dance. This resulted to the dichotomy between the so called dance scholars and pragmatic dance artists.

For the purpose of analysis in this paper, the researcher identifies two schools of thought among dance practitioners in Nigeria. They are theoretical dance artists and pragmatic dance artists. Similarly, Udoka (2006) in his articles titled "Dance in Search of a Nation: Towards a Sociopolitical Re-Definition of Dance in Nigeria" observed a division among the Nigerian traditional dancers. Udoka called them "the dance scholars" and "the popular local performers". He classified both groups as "predators" because in spite of their knowledge and authority, there was no correlation between their efforts.

\section{Theoretical Dance Artists}

In Nigeria, this group is concerned primarily with dance theories rather than practical applications. The dance scholars in this category believe that the practice/performance of dance cannot take one to a recognisable height. Scholars in this school of thought strongly believe that intellectualism is only associated with theoretical postulations and that it is superior to practical knowledge. In Nigerian the dance theorists are mostly found within the high institution of learning especially in Theatre or Dramatic Arts Department. Most of them are graduates of theatre arts that did not specialise in dance perhaps due to their inability to practically execute dance on stage as students. When they are engaged as lecturers, they are assigned to teach dance courses due to lack of qualified dance lecturers. In the attempt to justify their position as dance lecturers, they engage themselves in reading dance materials and topics like principles and elements of dance. Their teaching styles begins by explaining and describing what they read in dance books as they may not have enough experience in what they were teaching. Such so called dance lecturers normally end up in dividing the class into groups for practical presentations without aiding or teaching the students the practical aspects of the course.

Some dance scholars in this school of thought may be found in the research and documentation division of Arts Councils or Ministry of Culture. In some areas they are involved in the documentation of the arts and culture of the people. Because of their inexperience in dance arts, they end-up writing and documenting dance synopsis of different local government area rather than carrying out an in-depth research of such dances. This has resulted to lack of scholarly literature in dance especially among the research and documentation divi- 
sion/unit of Arts Councils in Nigeria. Within the higher institution of learning, some of the academics tend to recognise and almost worship scholars that only tilt towards theoretical postulations than practical studies. For Bakare, this attitude among scholars create academic imbalance and negates the principles and goals of learning. Concerning Sonni Oti, Bakare observes that:

Because of his overwhelming stature as a performer, armchair critics who already had the preconceived notion that his performative prowess negates ability for analysis myopically concluded that Sonny couldn't be intellectually sound. The result of all these is that Sonny was rendered the most unsung Nigerian hero, the most unknown theatre giant in Africa (Bakare, 1999: p. 8).

Others in this school of thought may be found in big government parastatals like the National Council for Arts and Culture, National Troupe and National Theatre. They may not be trained dance artist in practice or theory, but due to their long association with dancers and long-time experience in arts administration, they developed the interest of writing articles in dance studies. Though, there is no gainsaying that quite a hand-few of them have respect and regard for the artistry in the dance performers and have either through their dance publications or administration contributed to the development of dance in Nigeria while others see themselves as dance intellectuals with little or no regard for those in the practice of dance. Some of the scholars in this school of thoughts do not regard the dance practitioners as intellectuals. Concerning imbalance judgment on who an intellectual is, Bakare queried:

Why are those imbued with creative and performative abilities often thought of as having no intellectual capabilities? Is intellect not the sole facilitator of creative perfomative behaviour? Those who are gifted with creative and performative prowess know the centrality of intellectualism to the creative and performative process (Bakare, 1999: p. 7).

According to Bakare, intellectualism has often been seen as a non-populist activity from which emotions and intuition must be detached. This may neither be right nor wrong, depending on how far a so called intellectual has progressed away from humanism, but if intellectualism means having or showing good reasoning power, interest in the things of the mind, it means the manner and technique involved in the processing of these raw materials and the style of presentation employed in disseminating the resultant artistic information, which itself is an index of the level of maturity and artistry of the creative artiste, is definitely an intellectual procedure. Therefore, any creative artiste, whose works have been adjudged mature and truly artistic, is an intellectual (Bakare, 1999).

\section{Pragmatic Dance Artists}

By this, the researcher means dancers that are guided by practical experience and observation rather than theory. Such dancers believe that all that matters is the ability to execute dance on stage. Their opinion is that the end result of theoretical postulations in dance art is the ability to perform on stage for the audience. They queried that if they have the technical knowhow of executing dance performance on stage, what is the need of wasting a long period of time in theorising dance? The dance artist in this school of thought could be found in the performing arts department of Arts Councils, community and private dance troupes and among the freelance dance artists. Such dancers believe more in talents and practice rather than theoretical studies. Though very few of them went to school and studied courses that are not related to dance, but they found themselves in dance art as a result of their talents and practice. A dancer in this category sees the theorist (scholar) as opportunist and hijacker of what do not belong to him. Thus they accused the scholars of being jealous of their natural talents in dance. They are not comfortable working with the scholars especially on dance piece that involved research and that has literate society as target-audience. They prefer and can perform dances at short notice for politicians and business men as their mayor concern is the quick money that takes care of their immediate problems.

However, in Nigeria, there are also some up-growing dance practitioners and few mentors that believe in the combination of theoretical knowledge and practical abilities in dance art. Artists in this category are very few. Some started from the on-set of their profession to combine the two fields of knowledge while others started with the practice and later saw the need for the pursuit of theoretical knowledge. Those in this "unpopular" category are neither opportunists nor hijackers and in the words of Udoka, they are not also "predators". From the on-set and against all kinds of intimidation and cajoling, they believe in their profession and stayed-put. Gradually, they are advancing and developing the dance profession in Nigeria. 


\section{Synergy of Dance Theory and Practice}

Following the two schools of thought that has been identified and discussed above, there is need for them to work together for effective growth and development of dance in Nigeria. At the moment, there is no correlation between their efforts. The knowledge, authority and experience that each group possesses is yet to yield good result. Though, some the scholars have carried-out research and documentation that may help to gained insight into dance art and aids the researchers in understanding dance practice in Nigeria. On the other hand, the practitioners have tried to keep the spirit of dance alive in Nigeria through their performances. But each group working independently will not help to achieve the desired goals of dance developments in Nigeria. The writer identifies two major areas that needed to be re-organised and re-structured in our polity so as to foster the synergy of dance practice and theory and accelerate the progress of dance development. The areas are: inclusion of dance subject in education curriculum and collaborations among dance artists.

\section{Inclusion of Dance Subject in Education Curriculum}

It is surprising that till date, dance as a subject is not taught at the primary and secondary school levels in Nigeria. There are more than 70 federal and states higher institutions in Nigeria, none has dance as a full-fledged department. In some of the theatre arts departments, the study of dance as an academic subject virtually does not exist. Where it does exist at all, it serves as a support to drama in the departments of theatre arts. In fact, to say that you are specialising in dance studies is something that cannot be imagined even by fellow academics (Ugolo, 1994). As a result, only a few candidates apply to study theatre arts and specialise in dance, hence there are few dance scholars in the country who can actually defend and project the image and artistic potency of dance. It is not surprising therefore that most of the dance research materials available in Nigeria have been generated by theatre scholars.

Though the practice of dance is not new to Nigeria and Africa as it has been part of the people's life. Chris Ugolo captures the varied forms and styles of dance that covers many occasions in Nigeria and African society:

In the African society, dance is used to mark every event of life. There are dances to mark birth and transition from one age group to another. To celebrate the planting season and harvest, to mark the end of the year and beginning of another to mark status in society, dances of occupational groups and dances to mark and document import historical events (Ugolo, 1994: p. 71).

The role dance plays in everyday life of the Nigerians is vital and cannot be over-emphasise however, one wonders why the subject of dance is not included in the Nigerian primary and secondary school education curriculum. As a matter of urgency, Nigerian educational planners should include the subject of dance in the primary and secondary schools education curriculum. At the tertiary institutions and universities, introduction of practice-based degrees in dance and theatre arts departments will be of great help in the synergy of theory and practice of dance. Practice based studies (dance inclusive) is in all classes of degrees and is an area of specialisation in most academic institutions all over the globe especially in Australia, Europe and United Kingdom universities and does not negate the knowledge of theories. According to Candy:

Practice-based Research is an original investigation undertaken in order to gain new knowledge partly by means of practice and the outcomes of that practice. In a doctoral thesis, claims of originality and contribution to knowledge may be demonstrated through creative outcomes in the form of designs, music, digital media, performances and exhibitions. Whilst the significance and context of the claims are described in words, a full understanding can only be obtained with direct reference to the outcomes (Candy, 2006: p. 1).

Smith and Dean (2009), observes that creative work within the university environment is now often referred to as practice-led research, practice-based research, creative research or practice as research. They argue that the terminologies are a means to characterise the ways in which practice can result in research insights, such as those that arise out of making a creative work and or in the documentation and theorisation of that work (Smith \& Dean, 2009). Candy (2006) opines that in practice-based research, one of the bases of its contribution to knowledge is the creative process and its outcome. In terms of how to assess the effectiveness of practice/ practice-based research in dance, Christopher Frayling suggests that:

The practice based doctorate (research) advances knowledge partly by means of practice. An original/crea- 
tive piece of work is included in the submission for examination. It is distinct in that significant aspects of the claim for doctoral characteristics of originality, mastery and contribution to the field are held to be demonstrated through the original creative work (Frayling, 1997: p. 11).

Here, Frayling sets out clearly, that the submitted creative work must be judged by the same criteria as the written text. Vincs (2010) observes that dance practice has only recently begun to be articulated as a specific methodology for dance research. The idea that writing and dancing together define dance research has been embedded in the field for some time (ibid). Vincs' observation is a longstanding tradition in postgraduate dance education in which performance work is presented and accompanied by a written thesis. A minor thesis typically describes documents and articulates the philosophy of the student's artwork (Vincs, 2010). The attempts to clarify the methodological foundation of this theory are evident in.

Haseman's (2006) performative research theory is concerned with those researchers who carry out practice-led research. Practice-led research is intrinsically experiential and comes to the fore when the researcher creates new artistic forms. The "practice" in "practice-led research" is primary-it is not an optional extra; it is the necessary pre-condition of engagement in performative research. Performative research represents a move which holds that practice is the principal research activity—rather than only the practice of performance —and sees the material outcomes of practice as all-important representations of research findings in their own right. The principal distinction between this third category (the performative paradigm) and the qualitative and quantitative categories is found in the way it chooses to express its findings. In this case, while findings are expressed in non-numeric data, they can be presented as symbolic forms other than in the words of discursive text. Instead research reporting in this paradigm occurs as rich, presentational forms.

Some may argue that the practice/practical's in dance has long been one of the criterions for awarding a degree to theatre arts students that specialises in dance in the Nigerian universities. Yes, this is true but, the writer observed that the practice in dance studies in most Nigerian universities is an accompaniment to the theories and only a proof that the student being examines is capable of performing some dance movements. Here, the originality of the practice (dance piece), synergy of the theory and practice in most cases is not clear and is questionable unlike in "Practice-Based Research" which is an original investigation undertaken in order to gain new knowledge partly by means of practice and the outcomes of that practice (Candy, 2006). In such study, one of the bases of the contribution to knowledge is the practice, because the creative process and its outcome will answer the research questions. The practice is not just a mere accompaniment in the study. It drives the research. Therefore, it is important to include dance as a subject in the primary and secondary schools in Nigeria and to implement fully the synergy of dance theory and practice at all levels of degrees in Nigerian Universities because the lack of dance graduate artists has resulted to lack of research and scholarship and has led to the stunted growth of dance in the Nigeria. Moreover, the world is becoming a global village, Nigeria and other African countries will not operate in isolation rather will find it place and integrate issues that will be of benefit to them.

\section{Collaborations among Dance Artists}

The synergy of dance theory and practice could be enhanced through the collaborations of the Tertiary Institutions, Universities and other outfits where dancers are affiliated such as Arts Councils, Dance Companies and Dance Associations. Introducing a linkage programme between the Theatre Arts Departments of the different educational institutions and the Arts Councils will be of great help to the dancers. Most dancers in the Arts Councils and Dance Companies did not study dance or theatre arts in the higher institution of learning. They depend heavily on their practical abilities in dance execution with little or no theoretical knowledge of their arts. As earlier stated, for such dancers, dance performance starts and ends with the practice, they are not concerned with the theories. Some of them believe that it is the job of the scholars and choreographers to tell or give them an idea of what to do on stage. On the other, some dance graduate artists working with the tertiary institutions and universities including undergraduates prefer to identify with the theories of dance studies.

The collaboration between these bodies in terms of training, joint performances will encourage the dance artists among the Arts Councils, dance companies and freelance dancers to take up studies in dance, which will led to quality productions. According to Nadel and Miller (1978: p. 1), "The more we know about what we are working with, the better we will understand and, therefore enjoy it". The collaboration between the universities, Arts Councils and dance companies is necessary because dance studies involve lots of practical and in Nigeria, the Arts Councils environment appears more practical friendly than the universities, on the other hand Arts 
Councils dancers that may not have enough theoretical knowledge of the dance art and performances will now benefit from the university programs such as certificate courses, diplomas and conferences.

Also there are different dance bodies and association in Nigeria, such as Dancers Guild of Nigeria (DAGON), Dance Scholars Society of Nigeria (DASSON) and National Association of Nigerian Theatre Arts Practitioners (NANTAP). The above mentioned associations can organise periodic workshops and seminar for different dance companies, dance troupes and freelance artists across Nigeria. This will foster the synergy and enhance skills of the dancers. Dance artists need different skills to make a living from their art. Being skilled dancers, they ideally need good written and verbal communication skills, research skills, knowledge of health and safety, assessment and evaluation as well as the ability to identify useful contacts and sources of information and reflect on their practice in order to improve. For the purpose of the dance and training accreditation partnerships, the dance companies and troupes should work together with other associations in the dance sector to identify the key skills and areas of knowledge that dance leaders need across their career in order to develop and become more effective in their work.

\section{Conclusion}

The main aim of this study is to review the activities among dance practitioners in Nigeria by highlighting the dichotomy in the views between the dance scholars who are concerned primarily with dance theories rather than practical applications and their pragmatic counterparts who believe that all that matters is the ability to perform on stage for the audience and not the theoretical postulations in dance art. It suggests ways of enhancing a synergy of the two schools of thought that may lead to the growth and promotion of dance art in Nigeria. This synergy will encourage creativity among the artistes; increases out-put in dance performances and develop dance practices in Nigeria.

\section{References}

Bakare, O. R. (1999). The Artiste-Intellectual: Sonny Oti on Stage. Ibadan: Jofel Books.

Candy, L. (2006). Creativity \& Cognition Studios. In Practice-Based Research: A Guide. http://www.creativityandcognition.com

Clark, E. (1979). Hubert Ogunde: The Making of Nigerian Theatre. Oxford: Oxford University Press.

Frayling, C. (1997). Practice-Based Doctorates in the Creative and Performing Arts and Design. Lichfield: UK Council for Graduate Education.

Haseman, B. (2006). A Manifesto for Performative Research: Media International Australia Incorporating Culture and Policy, Theme Issue “Practice-Led Research”. Quarterly Journal of Media Research and Resources, 118, 98-106. http://eprints.qut.edu.au/3999/

Nadel, M., \& Miller, C. (1978). The Nature of Dance. In Myron, N., \& Constance, M. (Eds.), The Dance Experience: Reading in Dance Appreciation. New York: Universe Book, 1-2.

Nwankwo, N. (1977). Danda. Glasgow: William Collins Sons and Co Ltd.

Nwaru, C. (2008). Dance as a Signifying Practices: A Study of Uri-Agha. In Okagbuo, O. (Ed.), African Performance Review (Vol. 1-2). London: Adons \& Abbey Publishers Ltd., 29-42.

Nwoko, D. (1981). Search for a New African Theatre. In Yemi, O. (Ed.), Drama and Theatre in Nigeria: A Critical Source Book. Lagos: Nigerian Magazine, 462-478.

Smith, H., \& Dean, R. (2009). Introduction: Practice-Led Research, Research-Led Practice-Towards the Iterative Cyclic Wed. In: Hazel, S., \& Roger, D. (Eds.), Practice-Led Research, Research-Led Practice in the Creative Arts. Edinburgh: Edinburgh University Press, 1-40.

Udoka, A. (2006). Dance in Search of a Nation: Towards a Sociopolitical Re-Definition of Dance in Nigeria. In: Yerima, A., Rasaki, B., \& Udoka, A. (Eds.), Critical Perspectives on Dance in Nigeria. Ibadan: Kraft Books Limited, 276-292.

Ugolo, C. (1994). The State of Dance Research in Nigeria. Dance Research Journal, 26, 71-73. http://dx.doi.org/10.2307/1477938

Vincs, K. (2010). Rhizome/Myzone: A Case Study in Studio-Based Dance Research. In: Estelle, B., \& Babara, B. (Eds.), Practice as Research Approaches to Creative Arts Enquiry. London: I.B. Tauris \& Co Ltd., 99-112. 
Scientific Research Publishing (SCIRP) is one of the largest Open Access journal publishers. It is currently publishing more than 200 open access, online, peer-reviewed journals covering a wide range of academic disciplines. SCIRP serves the worldwide academic communities and contributes to the progress and application of science with its publication.

Other selected journals from SCIRP are listed as below. Submit your manuscript to us via either submit@scirp.org or Online Submission Portal.
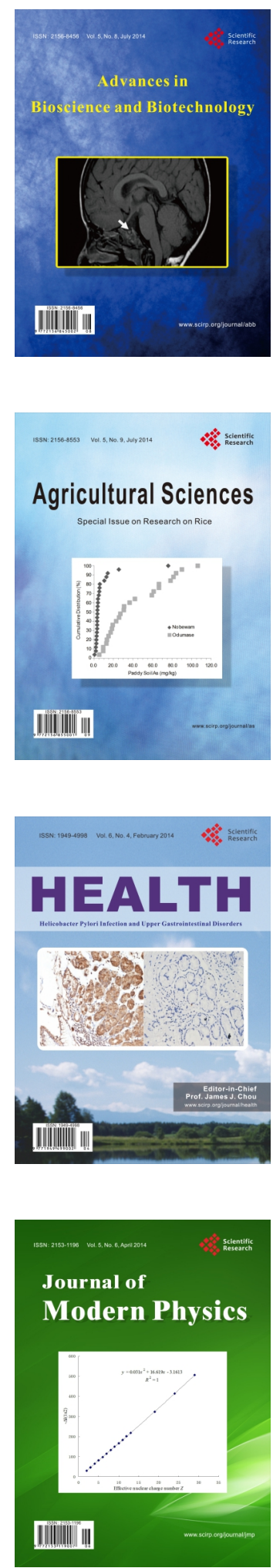
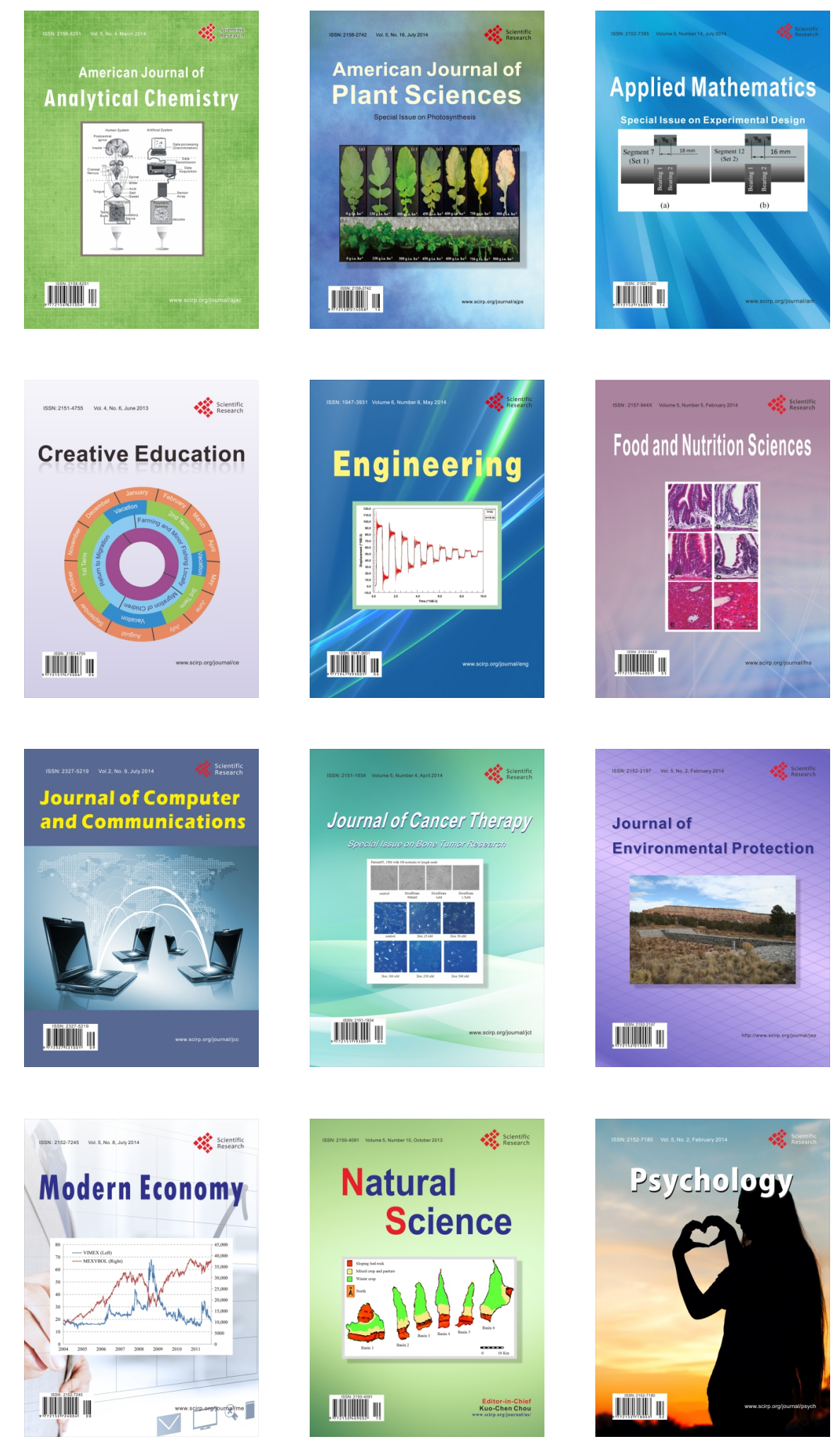